\title{
EFEKTIVITAS PENGGUNAAN JARING KABUT DALAM KOLEKSI CHIROPTERA (MEGACHIROPTERA DAN MICROCHIROPTERA)
}

\section{Effectiveness Of Using Mist Net In The Chiroptera Collection (Megachiroptera And Microchiroptera)}

\author{
Jason Thomas Karuntu* dan Annawaty \\ Jurusan Biologi Fakultas Matematika dan IImu Pengetahuan Alam Universitas Tadulako Tondo Palu, \\ Sulawesi Tengah 94118
}

Keywords: bats, trap effectivenes $\mathrm{s}$, mist net, Sulawesi.

\section{ABSTRACT}

The use of traps is very important in the process of sampling bats in the field. The mist net is a type of traps that commonly used to catch bats for research purposes. This study aims to determine the effectiveness of using mist nets in bats sampling. Sampling site located in the Lindu Plain, District of Sigi, Central Sulawesi. Bats were sampled by mist nets using purposive sampling method, at four different types of habitat. The result of this study indicated that mist net is effective in catching fruit-eating bats (Megachiroptera), but is not effective in capturing insectivorous bats (Microchiroptera).
Kata Kunci: Eksplorasi, Hoya, Gunung Sidole, Sulawesi Tengah

\section{ABSTRAK}

Penggunaan perangkap sangat penting dalam proses pengambilan sampel kelelawar di lapangan. Jaring kabut merupakan salah satu jenis jebakan yang biasa digunakan untuk menangkap kelelawar untuk keperluan penelitian. Penelitian ini bertujuan untuk mengetahui efektivitas penggunaan jaring kabut dalam pengambilan sampel kelelawar. Lokasi pengambilan sampel berada di Dataran Lindu, Kabupaten Sigi, Sulawesi Tengah. Kelelawar diambil sampelnya dengan jaring kabut menggunakan metode purposive sampling, di empat tipe habitat yang berbeda. Hasil penelitian ini menunjukkan bahwa jaring kabut efektif dalam menangkap kelelawar pemakan buah (Megachiroptera), namun tidak efektif dalam menangkap kelelawar pemakan serangga (Microchiroptera).

*Corresponding Author : Jasonthom96@gmail.com

\section{PENDAHULUAN}

Penangkapan kelelawar yang dilakukan untuk tujuan penelitian dapat menggunakan berbagai macam perangkap, termasuk menggunakan mist net (Whitaker and Mumford, 1971). Beberapa jenis perangkap lainnya yang juga digunakan untuk menangkap kelelawar, adalah double frame bat trap (Tuttle, 1974), collapsible bat-trap
(Tidemann and Woodside, 1978) dan tunnel nets (Griffin, 1940). Jenis perangkap yang terakhir hanya digunakan di ruang yang terbatas seperti gua ataupun di hutan.

Kelelawar merupakan mamalia bersayap yang termasuk ke dalam ordo Chiroptera dan dapat dibedakan dari semua mamalia lainnya dari kemampuannya yang dapat terbang (Mickleburgh et al., 1992; 
Suyanto, 2001; Primack and Corlett, 2005). Kelelawar digolongkan dalam ordo Chiroptera yang berarti mempunyai sayap tangan, karena anggota tubuh bagian depannya termodifikasi menjadi sayap, meskipun secara struktural berbeda dengan sayap pada burung. Sayap kelelawar terbentuk dari membran elastis berotot yang dinamakan patagium dan tidak berbulu. Sayap ini berfungsi untuk terbang dan menyelimuti tubuhnya ketika bergantung terbalik. Patagium pada kelelawar betina juga berfungsi untuk memegang anaknya yang baru dilahirkan dengan posisi kepala di bawah (Corbet and Hill, 1992; Feldhamer et al., 1999; Suyanto et al., 2002; Lekagul and McNeely, 1977).

Ordo Chiroptera terbagi atas dua subordo yaitu Megachiroptera (kelelawar pemakan buah) dan Microchiroptera (kelelawar pemakan serangga). Sesuai dengan namanya, anggota ordo Megachiroptera umumnya memiliki ukuran lebih besar dari Microchiroptera. Berat dari Megachiroptera sekitar 10-1.500 gram dan memiliki panjang lengan bawah 35-228 mm (Nowak et al., 1994). Megachiroptera memiliki ciri ciri: jari sayap kedua umumnya bercakar, mata besar, penciuman yang baik, struktur telinga sederhana dengan tepi yang membentuk cincin yang tidak terputus, tidak memiliki tragus/antitragus (struktur kecil di telinga), membran ekor biasanya sempit dan ekor umumnya pendek atau tidak ada, meskipun terdapat pengecualian pada ISSN-P : 1978-6417; ISSN-E : 2580-5991 genus Notopteris yang memiliki ekor yang agak panjang dan ekornya tidak terpisah dengan membran (Suyanto, 2001; Mickleburgh et al., 1992).

Microchiroptera memiliki panjang lengan berkisar 22,5-115,0 mm. Microchiroptera pada umumnya berukuran kecil, memiliki struktur telinga kompleks, memiliki tragus/antitragus yang merupakan bagian kulit berdiri di depan saluran telinga, jari sayap kedua tidak bercakar dan Microchiroptera mempunyai ekor yang relatif panjang. Beberapa famili dari subordo Microchiroptera memiliki hidung yang unik. Famili Rhinolophidae memiliki daun hidung sederhana, berupa lipatan kulit kecil (lapet) dan tumbuh di ujung moncong dan famili Hipposideridae memiliki wajah yang unik terutama disekitar hidungnya yang terdapat tonjolan kulit (lanset) yang dinamakan daun hidung (Hutson et al., 2001; Suyanto, 2001). Tujuan penelitian ini adalah untuk mengetahui efektivitas perangkap kelelawar yang digunakan terutama perangkap jaring kabut (mist net).

\section{BAHAN DAN METODE}

Penelitian ini dilaksanakan pada bulan Februari di Dataran Lindu, Sigi, Sulawesi Tengah (Gambar 1). Pengambilan sampel dibagi pada beberapa tempat, dimulai dari kebun multikultur (KMU) (01 1924.84 LS - 1203 3,25 BT), sisi hutan (SH) (01 20 40,5 LS - 12002 48,3 BT), kebun monokultur (KMO) (01 19 40,0 LS - 120 07 51,3 BT) dan sisi danau (SD) (01 19 33,7 LS - 12003 08,9 BT). Alat yang 
digunakan dalam penelitian ini ialah GPS (Global Positioning System) berfungsi untuk menentukan titik koordinat dan altitude, jaring kabut (mist net) berfungsi sebagai perangkap, tiang berfungsi sebagai penyangga perangkap dan head lamp berfungsi sebagai penerang.

\section{Prosedur Penelitian}

\section{Penentuan Lokasi Pemasangan Perangkap}

Penentuan lokasi pemasangan perangkap terlebih dahulu dengan melakukan survei di daerah tempat yang akan dijadikan pemasangan perangkap, untuk melihat pakan, sarang maupun arah terbang dari kelelawar. Hal ini dilakukan untuk memudahkan proses pemasangan perangkap. Pemasangan perangkap di bagian hutan, jaring dipasang menyusuri tepi hutan, atau punggung bukit, menyilang lorong-lorong atau jalan setapak yang diduga dilalui kelelawar.

Metode Pemasangan Perangkap dan Koleksi Sampel

Perangkap yang digunakan dalam penelitian ini yaitu jaring kabut (mist net) dengan ukuran lebar $12 \mathrm{~m} \times 5 \mathrm{~m}$. Penempatan perangkap menggunakan metode purposive sampling yaitu memasang perangkap pada lokasi yang dikehendaki.

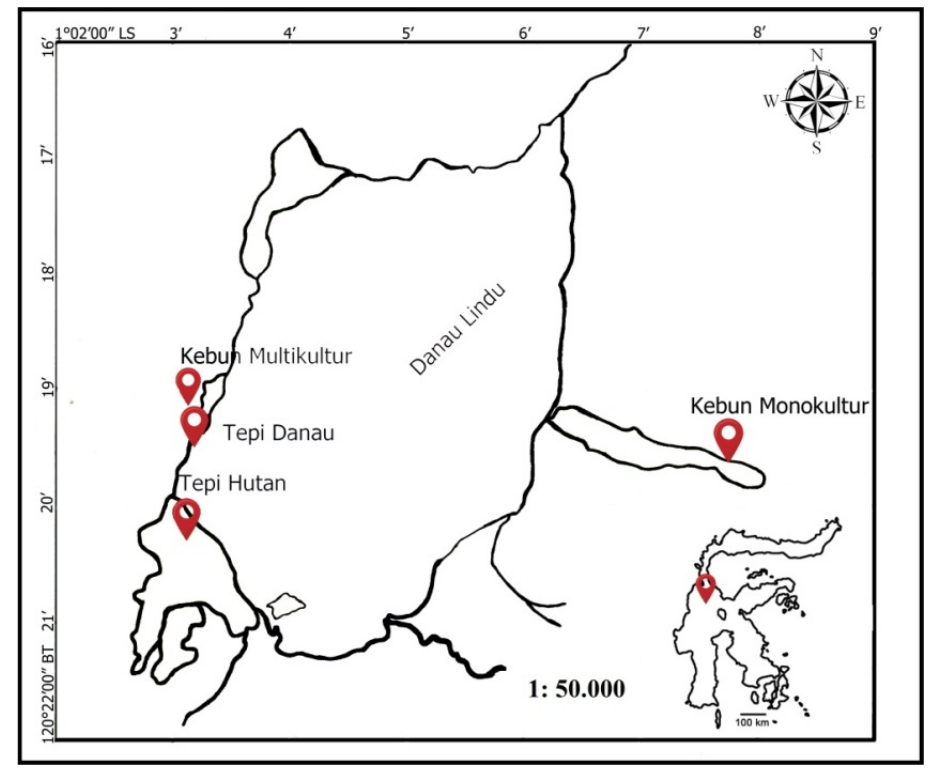

Gambar 1. Peta Lokasi Penelitian (Dataran Lindu)

Penangkapan kelelawar menggunakan perangkap jaring kabut (mist net) dan pada setiap stasiun dipasang satu jaring kabut. Pemasangan perangkap dilakukan pada pukul 16:30 sebelum kelelawar keluar dari sarang dan dilakukan pengecekan sekali pada pukul 00:00 untuk menghindari kelelawar yang lepas atau susah dilepaskan sehingga dapat melukai 
tubuhnya. Pelepasan jaring dilakukan pada pukul 05:00 sekaligus mengambil sampel yang telah terjerat di dalam jaring. Waktu pengambilan sampel hanya dilakukan satu kali.

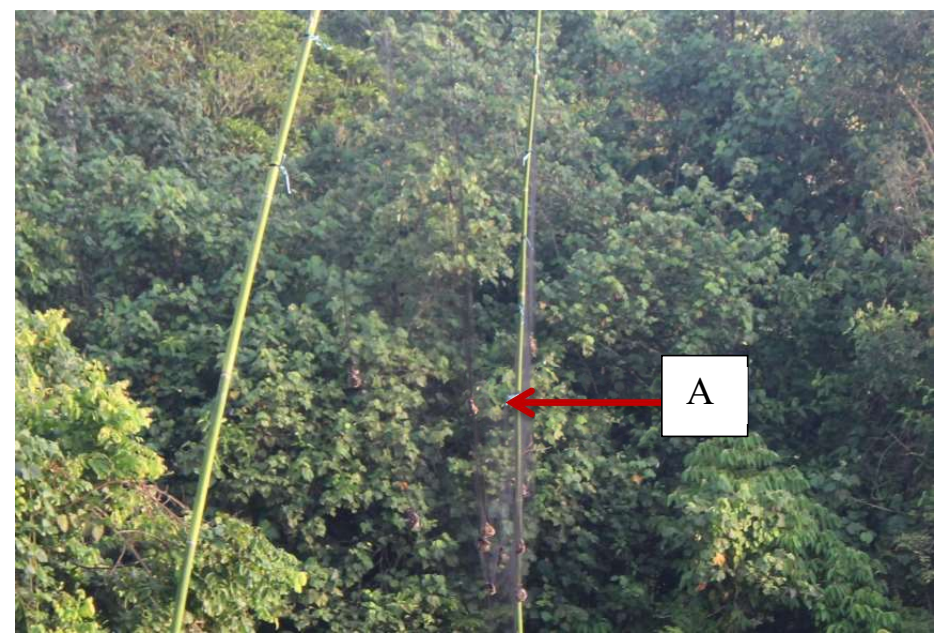

Gambar 2. Jaring kabut (mist net); A. Jaring kabut.

\section{HASIL DAN PEMBAHASAN}

Hasil penangkapan yang maksimal menggunakan mist net terdapat pada kelelawar subordo Megachiroptera, karena memiliki ukuran yang cukup besar yaitu berat sekitar 10-1.500 gram dan memiliki panjang lengan bawah 35-228 $\mathrm{mm}$ sedangkan mesh (lebar mata jaring) 30-32 $\mathrm{mm}$ dengan ketebalan benang jaring 80 Denier $=$ berat $9000 \mathrm{~m}$ benang nilon dalam gram) (Suyanto, 2001). Menurut Yuliadi et al., (2013), kelelawar Megachiroptera menggunakan matanya untuk menentukan jalannya, sehingga dalam penelitian ini Megachiroptera merupakan subordo yang paling banyak terjerat di perangkap jaring kabut karena jaring ini sangat sulit dilihat pada malam hari dengan ketebalan 80 Denier.

Hasil berbeda didapatkan untuk subordo Microchiroptera, pada subordo ini tidak ISSN-P : 1978-6417; ISSN-E : 2580-5991 ada kelelawar yang tertangkap menggunakan jaring mist net, hal ini menandakan bahwa perangkap mist net kurang maksimal jika digunakan untuk menangkap subordo ini. Menurut Yuliadi et al., (2013) subordo Microchiroptera memiliki mata yang kecil sehingga untuk terbang pada malam hari menggunakan ekolokasi, sehingga kelelawar subordo Microchiroptera dapat mengetahui adanya perangkap yang berada di dekatnya.

Alat penangkapan kelelawar dapat berupa jaring kabut (mist net), jaring harpa atau jaring serangga yang bertangkai. Penelitian yang dilakukan di New South Wales, Australia, penggunaan jaring harpa untuk menangkap kelelawar lebih efisien daripada jaring kabut, tetapi di Indonesia hasilnya justru sebaliknya, dan hanya kelelawar jenis tertentu yang bisa tertangkap dengan jaring harpa 
(Tidemann dan Woodside, 1978; Suyanto, 2001). Setiap perangkap mempunyai beberapa kekurangan seperti jaring kabut yang dapat robek karena digigit oleh kelelawar, jaring harpa yang hanya bisa menangkap kelelawar dengan jenis tertentu serta jaring serangga yang bertangkai hanya dapat digunakan di dalam gua.

Perbedaan habitat juga dapat mempengaruhi tingkat perbedaan jenis dari kelelawar di suatu wilayah. Sebagian besar Megachiroptera memilih tempat yang memiliki pohon-pohon yang besar sedangkan Microchiroptera lebih memilih tempat berlindung pada lubang-lubang batang pohon, celah bambu, pohon mati, jalinan rotan/herba hingga langit-langit rumah pada pemukiman penduduk (Prasetyo et al., 2011).

Faktor lain yang mempengaruhi keanekaragaman kelelawar yaitu pengaruh lingkungan terhadap jenis maupun jumlah kelelawar. Menurut Nurwidayati dan Nurjana (2018), pada saat cuaca cerah jumlah kelelawar lebih banyak dari pada saat cuaca mendung maupun hujan. Kelelawar memiliki batas toleransi suhu lingkungan terhadap suhu tubuhnya. Setiap jenis kelelawar memiliki kisaran suhu yang berbeda-beda terhadap tempat bertenggernya. Sebagian kelelawar bertengger pada suhu udara antara $26,67-32,22^{\circ} \mathrm{C}$.

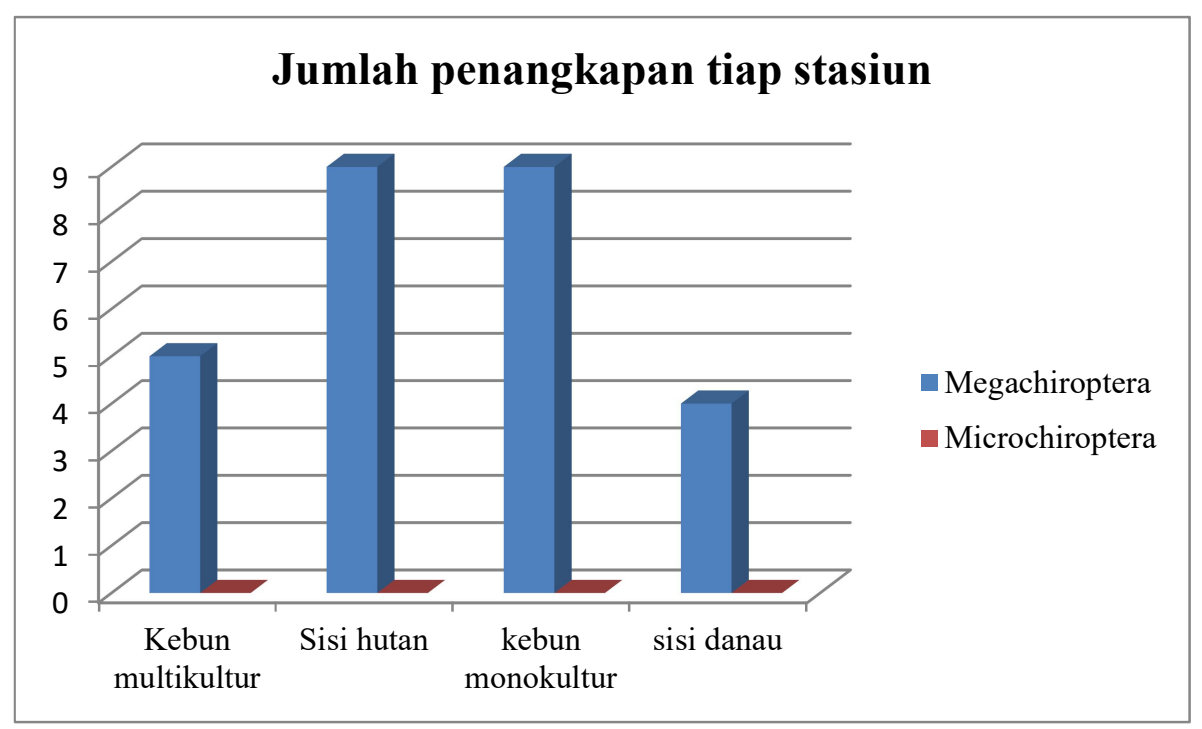

Gambar 3: Grafik jumlah penangkapan subordo kelelawar tiap stasiun.

\section{KESIMPULAN}

Berdasarkan hasil penelitian ini, dapat disimpulkan bahwa perangkap mist net efektif untuk menangkap kelelawar pemakan buah (Megachiroptera), namun tidak efektif untuk menangkap kelelawar pemakan serangga (Microchiroptera). 


\section{UCAPAN TERIMA KASIH}

Terima kasih kepada Camat Kecamatan Lindu, Sigi, Sulawesi Tengah yang telah memberikan izin untuk melakukan penelitian di sekitar Danau Lindu. Kepada Irfan S.Si, Evans Madiyono, S.Si, Mohamad Basit, Aswandi, Steven Stif Ladado, Praise Fransiska Malino, Ni Luh Setiawati yang telah membantu proses pengoleksian di lapangan.

\section{DAFTAR PUSTAKA}

Corbet, G. B., and Hill, J. E. 1992. The Mammals of the Indomalayan Region. A Systematics Review. Oxford (GB): Oxford Press.

Feldhamer, G. A., Drickamer, L. C., Vessey, S. H., Merritt, J. F., and Krajewski, C. 1999. Mammalogy: Adaptation, Diversity, Ecology 3rd ed. Boston Massachusetts (US): McGraw-Hill Co.

Griffin, D. R. 1940. Notes on the Lifes Histories of New England Cave Bats. Journal of Mammalogy, 21(2), 181-187.

Hutson, A., Mickleburgh S. P., and Racey, P. A. 2001. Microchiropteran Bats: Global Status Survey and Conservation Action Plan. Vol. 56. IUCN.

Lekagul, B., and McNeely, J. A. 1977. Mammals of Thailand. Association of Conservation of Wildlife. Bangkok, Thailand: Kurusapha Ladprao Press. 758 pp.

Mickleburgh, P. S., Anthony, M. H., and Paul, A. R. 1992. Old world fruit bats. An action plan for their conservation. Gland, Switzerland IUCN, 263.

Nowak, R. M., Walker, E. P., Kunz, T. H., and Pierson, E. D. 1994. Walker's Bats of the World. Baltimore and London: John Hopkins University Press.

Nurwidayati, A., dan Nurjana, M. 2018. Pengaruh Perbedaan Ekosistem dan Faktor Lingkungan Terhadap Keragaman Jenis Kelelawar di Kabupaten Tojo Una-Una dan Tolitoli Provinsi Sulawesi Tengah. Jurnal vektor penyakit. 12(2), 57-66.

Prasetyo, P. N., Noerfahmy, S., dan Tata, H. L. 2011. Jenis-jenis kelelawar Agroforest Sumatera. Bogor, Indonesia. World Agroforestry Centre - ICRAF, Sea Regional Office. $75 p$.

Primack, C., and Corlett, W. 2005. Tropical Rain Forest: An Ecological and Biogeographical Comparison. Malden, Oxford, Victoria: Blackwell Publishing.

Srinivasulu, C., Racey, P. A., and Mistry, S. 2010. A key to the bats (Mammalia: Chiroptera) of South Asia. Journal of Threatened Taxa, 2(7), 1001-1076.

Suyanto, A. 2001. Kelelawar di Indonesia. Puslitbang LIPI. Indonesia.

Suyanto, A., Yoneda, M., Maryanto, I., Maharadatunkamsi., and Sugardjito, J. 2002. Checklist of the Mammals of Indonesia: Scientific Names and Distribution Area Tables in Indonesia Catagories for Conservation. Bogor (ID): LIPI, JICA, and PHPA.

Tidemann, C. R., dan Woodside, D. P. 1978. A Collapsible bat-trap and a comparison of result obtained with the trap and with mist-nets. Australian Wildlife Research, 5: 355362 
Tuttle, M. D. 1974. An Improved Trap for Bats. Journal of Mammalogy, 55(2), 475-477.

Whitaker, J. O., and Mumford, R. E. 1971. Notes on a Collection of Bats Taken by Mist-Netting at an Indicana Caves. The American Midland Naturalist, 85(1), 277-279.
Yuliadi, B., Sari, T. K., and Handayani, F. D., 2013. Kelelawar Sulawesi Jenis dan Peranannya dalam Kesehatan. Lembaga Penerbit Badan Penelitian dan Pengembangan Kesehatan Kementrian Kesehatan RI. pp 114. 